\title{
Industrial Water Contamination and Health Impacts: An Economic Perspective
}

\author{
Azizullah Sayal, Shehla Amjad, Muhammad Bilal, \\ Arshid Pervez, Qaisar Mahmood*, Muhammad Asim Afridi \\ Department of Environmental Science, COMSATS Institute of Information Technology, \\ University Road, Tobe Camp, Abbottabad 22060, Pakistan
}

Received: 22 September 2015

Accepted: 10 November 2015

\begin{abstract}
The present study quantified and evaluated the presence of water pollution and its impact on the health of the adjacent human community. Water sampling and household surveying was carried out using a GIS approach using primary data. The quantification of health impact was based on the scientific tools of environment, economic theory, econometrics, and statistics. The focus of our study was the impact of lead $(\mathrm{Pb})$ contamination of drinking water from industrial effluents on population health and utility in Dingi village, adjacent to an industrial estate in Haripur Pakistan. Results of the study showed varying $\mathrm{Pb}$ contamination beyond the safe limits set by WHO. Marginal willingness to pay based on probabilities of sickness, medical costs, and avertive costs was estimated at $\$ 53$ per household yearly. The opportunity cost of leisure (\$22) and avertive measures (\$54) were also estimated to find the total economic cost born by households (\$300). Total annual welfare loss of the Dingi community exposed to $\mathrm{Pb}$ contamination and its cost accounted for 4.26 million PKR $(\$ 42,000)$. This welfare quantification extrapolated to other villages can contribute to heavy monetary loss. Policymakers should pay special attention to such polluted areas to adopt mitigation measures to save public health.
\end{abstract}

Keywords: dose response function, cost of illness, willingness to pay, welfare loss, industrial water pollution, environmental degradation, water $\mathrm{Pb}$ contamination

\section{Introduction}

Industrial wastewater contamination poses a serious threat to human and environmental health, especially in developing countries [1]. The availability of safe drinking water has been a serious menace in Pakistan either because of shortages or contamination by untreated industrial waste. The access of rural and urban populations

*e-mail: mahmoodzju@gmail.com to safe drinking water is estimated to be $23.5 \%$ and $30 \%$, respectively [2,3]. Most of the industrial estates in Pakistan were not established as per environmental regulations; therefore, industrial pollutant contamination is the main route of exposure [4]. $\mathrm{Pb}$ is one of those toxic elements that causes both acute and chronic diseases like high blood pressure, renal disorders, joint pain, and malfunctioning of the nervous system [5-7]. It is an admitted fact that most of the diseases are waterborne, either directly via the gastrointestinal tract or through exposure to contaminated water and food [8-10]. Communities in the vicinity of 


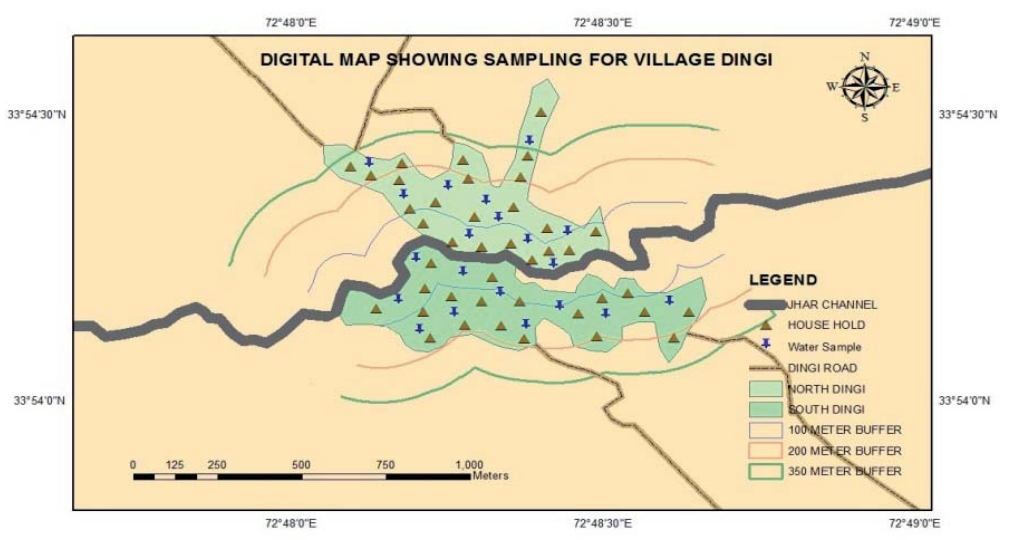

Fig. 1. GIS-based random sampling in Dingi village at increasing distances from wastewater channel.

industrial wastewater channels are more exposed to the worst health effects of these contaminants. The economic perspective on health focuses on the quantification of these health effects, which reduce their utility. The presence of heavy metal contamination and disease association is a fact proven by chemists, environmentalists, and epidemiologists. Experts in the natural sciences have also done a lot to establish the relationship between heavy metal pollution, its exposure, and health [11-15]. However, for the quantification of these health impacts, the costs of illness and prevention cost are required to be valued in monetary terms.

Multiple economic approaches have been devised for the quantification of health damage caused by environmental pollution [16-18]. These approaches include revealed preferences, stated preferences, contingent valuation, willingness to pay, etc. The fundamental ingredient for such an evaluation of health impacts is the health production function or dose response function. The health production function has been used to study the relationships among the pollution, illness, willingness to pay, and avertive expenses [19-21].

Cost of illness can be quantified by calculating loss of productivity, workdays lost, opportunity cost, and expenditures on medical treatment. Whereas the avertive cost estimation is based on all the precautionary measures to avoid the lethal effects of heavy-metal pollution. Applications and strengths of avertive expenditure techniques are particularly useful to reduce the level of discomfort arising from externalities, to estimate the willingness to pay, and to estimate the actual costs or benefits of drinking water quality [22-24]. However, avertive expenditures are defined differently for various types of pollution [25, 26]. Cost of illness and avertive costs approaches have also been used to estimate the welfare gains of air pollution reduction, arsenic removal from drinking water, and cement air pollution using health production function [26-31].

This study quantifies the environmental impact of $\mathrm{Pb}$ contamination in household drinking water in Dingi village, district Haripur, Pakistan. This village is situated in the southern part of Haripur district (Fig. 1), on the downstream banks of a wastewater channel named Jhar, which carries the untreated waste of the Hattar Industrial Estate (HIE) [32]. Our study is an attempt to quantify household damage due to industrial wastewater contamination in economic perspectives. Using the health production function, we estimated a marginal willingness to pay by calculating the medical and avertive expenditures incurred by the household. Finally, the welfare loss to the community was estimated. For econometric estimation, a probit model was applied to estimate the probability of sickness, plus medical and avertive costs. We also calculated the opportunity cost for leisure and avertive measures.

\section{Methodology \\ Village Profile}

Dingi village is highly prone to heavy metal (i.e., $\mathrm{Pb}$ ) contamination because of its geographical location (Fig. 1) surrounding HIE. This estate was developed in different phases. Installation of infrastructure facilities was finished at the end of 1989. An area of 700 acres was allotted to different industries such as ghee, fertilizer, chemical (sulfuric acid manufacturing plant and synthetic fiber manufacturing plant), and textiles. Currently 288 units of HIE are functioning. A major chunk of the population is

Table 1. Profile of Dingi village.

\begin{tabular}{|c|c|c|c|c|}
\hline Area $\left(\mathrm{km}^{2}\right)$ & Population & Households & Union council & Digital Arial Coordinates \\
\hline 0.2798 & 5021 & 350 & Dingi & $33^{\circ} 54^{\prime} 9.38^{\prime \prime} \mathrm{N}$ \\
\cline { 3 - 4 } & & & $72^{\circ} 48^{\prime} 20.88^{\prime \prime} \mathrm{E}$ \\
\hline
\end{tabular}


Table 2. GIS-based-water/household sampling from wastewater channel (Jar).

\begin{tabular}{|c|c|c|c|c|c|}
\hline $\begin{array}{c}\text { Sampling zones } \\
\text { location }\end{array}$ & $\begin{array}{c}\text { Distances } \\
(\mathrm{m})\end{array}$ & Household samples & Household water samples & Sick & Sickness (\%) \\
\hline 1 & 100 & 132 & 35 & 105 & 79 \\
\hline 2 & 200 & 99 & 35 & 55 & 55 \\
\hline 3 & 350 & 231 & 35 & 188 & 12 \\
\hline Total & & 350 & 105 & 53 \\
\hline
\end{tabular}

living on the southern bank of the wastewater channel that carries the untreated industrial waste (Table 1).

\section{Sampling Design}

Sampling design was comprised of primary data collected in three stages: i) Water sampling from the wastewater channel, ii) water sampling from households drinking water sources, and iii) household survey for relevant information through a customized questionnaire. Arc-GIS software was used to map the sampling area. Total area of Dingi is $0.2798 \mathrm{~km}^{2}$ (Table 1), whereas the community living around the wastewater channel is scattered over an area of $0.19 \mathrm{~km}^{2}$.

Geographically, the community occupies an area 500 $\mathrm{m}$ from the wastewater channel. Therefore, the entire population was distributed in three buffer zones: $100 \mathrm{~m}$, $200 \mathrm{~m}$, and $350 \mathrm{~m}$ (Table 2) from the wastewater channel. Sampling points were obtained on GPS coordinates (Fig. 1). Water samples were collected as per standard protocol. $\mathrm{Pb}$ concentration was determined by an atomic absorption spectrometer (Model AA700 PerkinElmer, USA).

\section{Pilot Survey and Household Sampling}

A pilot survey was also conducted on-site with an aim to establish the basis for research questions and also to avoid bias in primary data collection. Certain limitations were expected, like a negative response about the presence of contamination, especially from those respondents who were directly employed in nearby industry. This bias was reduced through repeated water sampling of households, although their percentage was not enough to create bias. The other limitation was availability of respondents due to work. So Friday was chosen for collecting the data from a maximum number of respondents because the majority $(90 \%)$ offer an obligatory Friday prayer, which resulted in a response rate above $80 \%$.

A household survey (Table 2) was conducted to collect seven types of information:

1. General characteristics regarding income, age, education, family size, etc.

2. Demographic and socio-economic characteristics of individuals.

3. Health status, illness, medical expenses, transportation, loss of income, sick days, disease frequency, absenteeism, holidays, etc.
4. Information about the pollution and its dangers.

5. Perceptions about contamination and lead-induced diseases.

6. Various types and costs of avertive measures adopted by the community.

7. Degree of exposure to contaminated water.

Table 2 describes the sampling design for the collection of data pertaining to water quality and household health information. The community living around the industrial wastewater channel was distributed into three zones of various distances. Sampling zones 1, 2, and 3 were 100,200 , and $350 \mathrm{~m}$, respectively, from the industrial wastewater channel (Fig. 1). With respect to the proportion of the population, 132 households were selected from zone 1, 99 from zone 2, and 231 from zone 3 . For water quality we obtained 35 samples of household drinking water for each zone. It is evident from Table 2 that households living away from the wastewater channel have a lower percentage of sickness, i.e., $79 \%$ in zone $1,55 \%$ in zone 2 , and $12 \%$ in zone 3 . We applied an econometric estimation based on economic theory (health production function) to investigate the relationship between a household's health and other factors.

\section{Estimating Health Production Function (Probit Model)}

The dependent variables of sickness, avertive expenditures, and medical costs are used as the binary variables in this model. Econometric estimation based on theoretical framework was carried out, and the probability of sickness was calculated using the probit model (Table 5).

These probability estimations were obtained using a probit model by maximizing the following log-likelihood function:

$$
\mathrm{L}=\sum\left(Y_{i} \ln F(x, \beta)+\left(1-Y_{i}\right)(1-\ln F(x, \beta)\right.
$$

...where $\mathrm{x}$ is a vector of independent variables and $\beta_{\mathrm{s}}$ are the coefficients that include:

- Individual-level information such as age measured in years;

- Education measured in five stages (primary, middle, high school, intermediate, and above);

- Monthly income (PKR);

- Lead concentration $\left(\mathrm{mgL}^{-1}\right)$; 
- Binary variables if the household adopts (1) or otherwise 0;

- Pr measures the perception of risk;

- Pollution awareness;

- Location in three categories (meters);

- FS measures the number of persons in a household's family.

$\mathrm{F}(\mathrm{x}, \beta)$ is the cumulative probability function for probit model. The dependent variable $Y_{i}$ is 1 if lead induced sickness exists, otherwise it is 0 if absent for the $\mathrm{i}^{\text {th }}$ households.

Fundamental requirement for empirical analysis was to determine the probability of sickness defined in the following equation:

MWTP $=\mathrm{w}_{\mathrm{i}} * \mathrm{WDL} * \mathrm{P}_{\mathrm{i}}(\mathrm{S} / \Delta \mathrm{C})+\mathrm{M} * \mathrm{P}_{\mathrm{i}}(\mathrm{M} / \Delta \mathrm{C})+\mathrm{A} * \mathrm{P}_{\mathrm{i}}(\mathrm{A} / \Delta \mathrm{C})$

...where $\mathrm{A}$ is the wi*WDL* $\mathrm{Pi}(\mathrm{S} / \Delta \mathrm{C})$, which measures the marginal impact in terms of income loss due to change in the level of exposure to lead $(\Delta \mathrm{C})$; $\mathrm{B}$ is the $\mathrm{M} * \mathrm{Pi}(\mathrm{M} / \Delta \mathrm{C})$ that measures the marginal changes in medical costs due to changes in exposure to lead $(\Delta \mathrm{C})$; and $\mathrm{C}$ is the $\mathrm{A} * \operatorname{Pi}(\mathrm{A} / \Delta \mathrm{C})$, which measures the marginal effect on avertive expenditures at the individual level due to changes in exposure to lead $(\Delta \mathrm{C})$. The resource opportunity cost is also called the cost of illness, which accounts for real cost in terms of productivity loss and the increase in the resources used for medical care.

The environmental effects of water contamination on health can reduce people's well-being through the following channels:

- Cost of disease treatment due to changes in environmental quality, and the opportunity cost of time on treatment (direct cost);

- Loss of wages during illness (indirect cost);

- Averting or defensive expenditures and activities associated with attempts to prevent diseases caused by the environmental quality changes.

\section{Results}

\section{Descriptive Statistics}

The community's exposure was determined in five areas: drinking, bathing, cooking, washing, and religious cleanliness (ablution) (Table 3 ). The average exposure was 3.36 out of 5 , which meant people were highly exposed to the contaminated water. Out of total households, $45 \%$ adopted one or more avertive measures. Location variable reflected that most of the people were residing in zones 1 and 2 of our sampled area, which meant $65 \%$ of the population was residing within a $200 \mathrm{~m}$ radius of the wastewater channel. Based on the responses to the questions set in the questionnaire, $38 \%$ of households had the means of communication and pollution awareness; whereas $49 \%$ of people perceived the higher risk of illness, but their perception was due to their specific concern over lead contamination and its fatal effects. Among bad habits, $19 \%$ of people had a smoking habit.

The average age of the respondents in the surveyed household was 40 years. Sickness reflects the percentage of the household among the sample of 350. It was found that $54 \%$ of households were suffering from one or more renal diseases. A large number of households was found to be on daily wages; therefore, the average income of the household was calculated as PKR19,460 per month (\$191). Education of the household was determined in five stages: 1) primary, 2) middle, 3) high school, 4) intermediate, and 5) above.

Table 3 showed that average education level of the household in Dingi was 1 and 2, implying that the average household is middle. $\mathrm{Pb}$ is the industrial contaminant from the wastewater channel and has been found in household drinking water. Average concentration of lead in the drinking water of the household is $0.25 \mathrm{mg} \mathrm{L}^{-1}$, $0.18 \mathrm{mg} \mathrm{L}^{-1}$, and $0.07 \mathrm{mg} \mathrm{L}^{-1}$ in zones 1, 2, and 3, respectively (Table 4). Medical cost is the out-of-pocket cost incurred by the household on illness caused by water contamination. It was found that $54 \%$ of households incurred medical costs. Avertive cost was the cost incurred by the household on adoption of one or more avertive measures. The avertive measures were adopted by $45 \%$ of households, thereby $45 \%$ of households incurred the avertive cost.

\section{Level of $\mathrm{Pb}$ Contamination}

All the samples from the wastewater channel and from household drinking water were found to exceed safe limits of $\mathrm{Pb}$ contamination standard value $(0.05)$ set by WHO for Pakistan (Table 4). Lead contamination has also been reported to be fatal in tap water [33], and young children have been exposed to water containing $\mathrm{Pb}$ [34].

\section{Estimating Probability of Sickness}

Using the probit model, probability of sickness (dose response function) and the marginal effects of various factors on the dependent variable of sickness were calculated with respect to the change in $\mathrm{Pb}$ concentration in drinking water. This showed the effect on changes in the probability of reducing the incidence of $\mathrm{Pb}$-related sickness when $\mathrm{Pb}$-contaminated water was replaced with safe mode.

Table 5 showed that a $19 \%$ reduction in the probability of sickness for the one unit decreased in the $\mathrm{Pb}$ concentration in drinking water source. It measures the benefit in terms of disease prevalence reduction by bringing the quality of water to "safe mode." Five kinds of activities define $\mathrm{Pb}$ exposure to the household, which is consuming water, bathing, ablution, cooking, and washing. The Muslim practice of ablution was found to be a major contributor to $\mathrm{Pb}$ exposure because people took water into their mouths five times daily, which might be ingested coming in contact with gums and throat, thereby causing black gums and diseases. 
Table 3. Descriptive statistics.

\begin{tabular}{|c|c|c|c|c|c|}
\hline Variable & No. of Observations & Mean & Std. Dev & Min & Max \\
\hline Exposure & 350 & 3.366 & 1.469 & 0 & 5 \\
\hline Avertive Measures (AM) & 350 & 0.457 & 0.499 & 0 & 1 \\
\hline Lead Concentration (Pb) & 350 & 0.170 & 0.258 & 0 & 1.656 \\
\hline Location & 350 & 1.949 & 0.838 & 1 & 3 \\
\hline Pollution Awareness (POLAWAR) & 350 & 0.380 & 0.486 & 0 & 1 \\
\hline Education (EDU) & 350 & 1.886 & 0.904 & 0 & 3 \\
\hline Income & 350 & 19460.7100 & 10060.4200 & 6750 & 55000 \\
\hline Risk Perception (Pr) & 350 & 0.491 & 0.501 & 0 & 1 \\
\hline Age & 350 & 40.751 & 11.556 & 21 & 72 \\
\hline
\end{tabular}

Table 4. Average values of lead concentrations in drinking water of households and wastewater.

\begin{tabular}{|c|c|c|c|}
\hline \multirow{2}{*}{$\begin{array}{c}\text { Lead, wastewater } \\
\text { channel }\left(\mathrm{mg} \mathrm{L}^{-1}\right)\end{array}$} & \multicolumn{2}{|c|}{ Lead in household drinking water sources $\left(\mathrm{mg} \mathrm{L}^{-1}\right),(\mathrm{n}=35)$} & \multirow{2}{*}{$\begin{array}{c}\text { Safe limit } \\
\left(\mathrm{mg} \mathrm{L}^{-1}\right)\end{array}$} \\
\cline { 2 - 5 } & \multicolumn{2}{|c|}{ Distance from wastewater water channel } & \multirow{2}{*}{0.05} \\
\cline { 2 - 5 } 1.58 & $100 \mathrm{~m}$ & $200 \mathrm{~m}$ & $350 \mathrm{~m}$ \\
\hline
\end{tabular}

It was revealed that exposure to contaminated water had a positive sign with probability of sickness and describes the reduction of sickness by $8 \%$ upon the one unit increase of exposure. The location of a residence in relation to the wastewater channel also plays a highly significant role for disease prevalence, which indicates $16 \%$ probability of sickness per unit change of distance. Households closer to the wastewater channel have more probability of sickness and vice versa. On the part of households, the study shows the ineffectiveness of education in bringing about a change in sickness (Table 5). In the study area, people take the avertive measures assuming two significant factors: general knowledge of pollution (POLAWAR) and specific knowledge of contaminants (Pr, perception of risk). Our estimates show that POLAWAR and Pr play important roles in the reduction of probability of sickness by $18 \%$ and
$6 \%$, respectively. Avertive measures also play a vital role in the reduction of sickness. One unit change in adopting the avertive measures brings $18 \%$ change in the probability of sickness. Signs of all the significant variables were consistent to the theory.

\section{Probability of Medical Costs}

Medical expenses are those which are incurred by the household due to $\mathrm{Pb}$-induced illness. They were estimated using the probit model (Table 6).

Mitigating activities refer to the measures taken after illness for the reduction of disease and its after-effects. They include various components of expenditures: visits to the doctor, consultancy fees, pathological tests, treatment, hospital fees, transportation costs, etc. The

Table 5. Probability and marginal effects of sickness/dose-response function.

\begin{tabular}{|c|c|c|c|c|c|c|c|}
\hline Sickness & Coeff. & Std. Err. & $\mathrm{z}$ & $\mathrm{P}>\mathrm{z}$ & $\mathrm{dy} / \mathrm{dx}$ & Std. Err. & ey/ex \\
\hline Exposure & 0.476 & 0.072 & 6.65 & 0.000 & 0.0803 & 0.0098 & 1.164 \\
\hline $\mathrm{AM}$ & -1.117 & 0.213 & -5.25 & 0.000 & -0.188 & 0.031 & -0.809 \\
\hline Location & -0.979 & 0.134 & -7.31 & 0.000 & -0.165 & 0.017 & -2.470 \\
\hline POLAWAR & -1.089 & 0.216 & -5.04 & 0.000 & -0.184 & 0.032 & -0.744 \\
\hline $\mathrm{Pr}$ & -0.387 & 0.206 & -1.88 & 0.060 & -0.065 & 0.034 & -0.266 \\
\hline $\mathrm{EDU}$ & -0.061 & 0.116 & -0.53 & 0.598 & --- & --- & -- \\
\hline $\mathrm{Pb}$ & 1.131 & 0.476 & 2.37 & 0.018 & 0.190 & 0.078 & 0.108 \\
\hline Constant & 1.534 & 0.464 & 3.31 & 0.001 & --- & --- & - \\
\hline
\end{tabular}

No of observations $=350$, LR chi-square $(7)=270.82$, Prob $>$ chi-square $=0.000$, Pseudo $R^{2}=0.562$, Log Likelihood $=-106.072$ 
Table 6. Probability and marginal effects of medical costs.

\begin{tabular}{|c|c|c|c|c|c|c|c|}
\hline Medical Cost & Coeff. & Std. Err. & $\mathrm{z}$ & $\mathrm{P}>\mathrm{z}$ & $\mathrm{dy} / \mathrm{dx}$ & Std. Err. & ey/ex \\
\hline Exposure & 0.465 & 0.073 & 6.37 & 0.000 & 0.079 & 0.01 & 1.153 \\
\hline $\mathrm{AM}$ & -1.058 & 0.211 & -5.01 & 0.000 & -0.177 & 0.031 & -0.778 \\
\hline Location & -0.985 & 0.136 & -7.25 & 0.000 & -0.165 & 0.017 & -2.503 \\
\hline POLAWAR & -1.239 & 0.218 & -5.68 & 0.000 & -0.207 & 0.031 & -0.870 \\
\hline $\mathrm{Pr}$ & -0.541 & 0.207 & -2.61 & 0.009 & -0.091 & 0.034 & -0.382 \\
\hline $\mathrm{EDU}$ & 0.001 & 0.117 & 0.01 & 0.9900 & --- & -- & -- \\
\hline $\mathrm{Pb}$ & 0.817 & 0.454 & 1.8 & 0.0720 & 0.1367 & 0.0748 & 0.083 \\
\hline Constant & 1.614 & 0.472 & 3.42 & 0.0010 & --- & -- & -- \\
\hline
\end{tabular}

No of observations $=350$, LR chi-square $(7)=271.48$, Prob $>$ chi-square $=0.0000$, Pseudo R2 $=0.5621$,

Log Likelihood $=-105.74245$

probability of medical expenses of the household can be reduced by $13 \%$ for a one-unit change in $\mathrm{Pb}$ concentration in drinking water, whereas $16 \%$ if the household is located away from the contaminated source (Table 6). Avertive measures contribute a vital role in reducing the probability of medical expenditure by $17 \%$ because people adopt avertive measures as a last resort. Since they cannot move away they have made a decision to live with the risks and believe in avertive measures to avoid sickness.

As in probability of sickness, pollution awareness and perception of risk have a significant impact in reducing the probability of incurring medical expenditure by $20 \%$ and $9 \%$, respectively. Income and education of the household are not significant because the village has a different culture compared to an urban community. Living in a joint family system is a village custom. Therefore, they borrow money from relatives, sell items, or draw money from a common pool managed at the community level.

\section{Probability of Avertive Costs}

Household avertive action decisions were based on three steps:

1. Whether or not to take avertive action.
2. Choosing the number and type.

3. Deciding on the amount of avertive expenditure.

Explanatory variables explaining avertive expenditures include location relative to the wastewater channel, $\mathrm{Pb}$ contamination in drinking water, knowledge of how pollution pertains to waterborne disease, risk perception and exposure to $\mathrm{Pb}$ contamination, level of education, avertive measures, and medical costs.

Avertive activities are the adoptions made by the household to prevent the impact of $\mathrm{Pb}$ contamination. Avertive measures adopted by the household include boiling water, chlorination, purchasing bottled water, and a filter cartridge. However, installing filter cartridges was expensive. But the most frequently used, effective, and cheapest measure was boiling water at the household level. Chlorination is also less expensive but it was not as popular as boiling water.

Household avertive decisions were considered as a two-step process in Dingi village. A probit regression model was used to determine factors that influence avertive actions. The dependent variable was equal to one if the household took at least one avertive action against $\mathrm{Pb}$ contamination, and zero in the case of no action. Table 7 shows the coefficient values and the marginal effects associated with the avertive measures.

Table 7. Probability and marginal effects of avertive costs.

\begin{tabular}{|c|c|c|c|c|c|c|c|}
\hline Avertive cost & Coeff. & Std. Err. & $\mathrm{Z}$ & $\mathrm{P}>\mathrm{z}$ & $\mathrm{dy} / \mathrm{dx}$ & Std. Err. & ey/ex \\
\hline Income & 0.0000321 & $7.61 \mathrm{E}-06$ & 4.22 & 0.000 & $1 \mathrm{E}-05$ & $2.22 \mathrm{E}-06$ & 0.490 \\
\hline Location & 0.059 & 0.093 & 0.63 & 0.527 & --- & --- & -- \\
\hline POLAWAR & 0.796 & 0.157 & 5.08 & 0.000 & 0.250 & 0.044 & 0.156 \\
\hline $\mathrm{Pr}$ & 0.431 & 0.164 & 2.63 & 0.009 & 0.135 & 0.050 & 0.144 \\
\hline $\mathrm{EDU}$ & 0.156 & 0.091 & 1.72 & 0.086 & 0.049 & 0.028 & 0.239 \\
\hline $\mathrm{Pb}$ & 0.846 & 0.311 & 2.72 & 0.006 & 0.266 & 0.095 & 0.120 \\
\hline Constant & -1.813 & 0.297 & -6.1 & 0.000 & --- & -- & - \\
\hline
\end{tabular}

No of observations=350,LR chi-square $(6)=93.52$, Prob $>$ chi-square $=0.0000$, Pseudo R2=0.1938, Log Likelihood $=-194.556$ 
Table 8. Calculation of cost of illness.

\begin{tabular}{|c|c|c|}
\hline Indicators & Estimated value & Comments \\
\hline Average wage rate & $648(\mathrm{PKR})$ & actual average wage rate \\
\hline $\begin{array}{c}\text { Average work days loss per } \\
\text { individual per year }\end{array}$ & 9 & days per year \\
\hline $\mathrm{P}(\mathrm{S} / \Delta \mathrm{C})$ & 0.190 & marginal effects of Pb contamination on sickness (Table 5) \\
\hline $\mathrm{P}(\mathrm{M} / \Delta \mathrm{C})$ & 0.137 & marginal effects of Lead contamination on medical cost (Table 6) \\
\hline $\mathrm{P}(\mathrm{A} / \Delta \mathrm{C})$ & 0.266 & marginal effects of Lead contamination on avertive cost (Table 7) \\
\hline Medical expenditure & $12,807.9(\mathrm{PKR})$ & \\
\hline Avertive expenditure & $10,260(\mathrm{PKR})$ & \\
\hline
\end{tabular}

Table 7 shows that pollution awareness, risk perception, income, and formal education play a significant role in determining avertive cost. However, the lowest impact is observed for education among all the variables. A one-unit increase in pollution awareness, risk perception, and formal education is likely to increase the probability of incurring avertive cost by 25,13 , and $4 \%$, respectively. Results reflect that $42 \%$ of household adopted at least one avertive measure, i.e., boiling of water, chlorination, purchasing bottled water, and filter cartridges. The costs of illness and welfare loss are given in Table 8.

\section{Cost of Illness and Welfare Loss}

The resource opportunity cost approach (also called cost of illness) accounts for real cost in terms of productivity loss and the increase in the resources used for medical care. The environmental effects of water contamination on health can reduce people's wellbeing through the following channels.

1. Cost of disease treatment caused by environmental quality changes (direct cost);

2. Loss of wages during illness (indirect cost);

3. Averting or defensive expenditures and activities associated with attempts to prevent diseases caused by the environmental quality changes.

Therefore, cost of illness based on the marginal effects of $\mathrm{Pb}$ contamination on the probability of sickness, medical costs, and avertive costs was calculated for the lower bound of marginal willingness to pay. Table 8 exhibits the calculation of cost of illness.

\section{Estimation of Marginal Willingness to Pay per Household (MWTP) (PKR)}

For the estimation of $\mathrm{MWTP}^{1}$, we estimated a threedemands equation: probability of sickness, probability of

\footnotetext{
${ }^{1}$ A person's willingness to pay for something shows the dollar value she attaches to it. Her willingness to pay for one more unit of a good is thus a dollar measure of the benefits the extra unit of the good gives her. As a result, the terms "willingness to pay" and "marginal benefit" are often used interchangeably.
}

medical cost, and probability of avertive cost (Tables 5, 6 , and 7).

MWTP is calculated by putting the estimated values of loss of income, plus medical and avertive expenditures along with their marginal effects.

$$
\begin{gathered}
\text { MWTP }=648 * 09 * 0.1905+ \\
+12807 * 0.1360+10260 * 0.2660 \\
\text { MWTP }=1110.996+1741+2729.16
\end{gathered}
$$

MWTP per household/per year $=5581.156$ PKR (\$55) (with respect to marginal effects)

\section{Average Economic Cost}

Average cost of illness, average avertive cost, average opportunity cost of the leisure hour, and the average opportunity cost of avertive measures were used to calculate the total economic cost as given below:

Average economic cost of Lead contamination = $12,807.9+10,260+2,302+5,654=31,023.9$ PKR (\$304.29) (Table 8, Fig. 2). Fig. 2 shows the composition of various costs incurred by the household on health due to $\mathrm{Pb}$ contamination. Loss of earnings (LOI) per household per year was $6 \%$, cost of illness (COI) was of $13 \%$, costs incurred by taking avertive actions (AC) was of 19\%, and opportunity cost of leisure hour (OPCLH) was $18 \%$, whereas the opportunity cost of raking avertive measures (OPCAM) was $44 \%$ per year.

\section{Welfare Loss}

Using the results of estimates in Tables 5, 6, and 7, the welfare loss to the population of Dingi was measured from water contamination. This study attempted to value the total numbers of sick days in monetary terms by taking into account the workdays lost (absent days), the medical costs, and costs of averting activities to arrive at welfare loss. Tables 9 and 10 comprehend these concepts: The amount of daily wages lost due to absence from work 


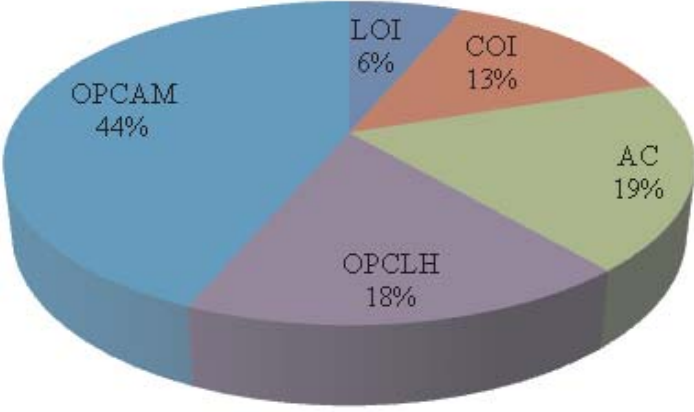

Fig. 2. Total economic cost equal to the sum of loss of income (LOI), cost of illness (COI), avertive cost (AC), opportunity cost of leisure hour (OPCLH), and opportunity cost of avertive measures (OPCAM)

may be taken as the cost of workdays lost due to water contamination-induced sickness for working individuals.

\section{Procedure to Calculate Welfare Loss in Table 10}

Column 1.

Total population of Dingi $=5,021$

Column 2

Col. $1 * \mathrm{P}(\mathrm{S} / \Delta \mathrm{C})=502 * 0.190=956.500$

Column 3.

WDL $($ Table 8$) * \operatorname{col} .2($ Table 9$)=9 * 956.50=8,608.504$

Column 4

Table 9. Indicators used in calculating welfare loss due to $\mathrm{Pb}$ contamination.

\begin{tabular}{|c|c|}
\hline Population at risk & 5021 \\
\hline Probable affected people & 956.500 \\
\hline Average loss of earnings & $6,251 \mathrm{PKR}$ \\
\hline $\begin{array}{l}\text { Probability of sickness with respect to changes } \\
\text { in } \mathrm{Pb} \text { concentrations }(\mathrm{S} / \Delta \mathrm{L})\end{array}$ & 0.190 \\
\hline $\begin{array}{l}\text { Probability of medical costs with respect to } \\
\text { changes in } \mathrm{Pb} \text { concentrations }(\mathrm{M} / \Delta \mathrm{L})\end{array}$ & 0.1367 \\
\hline $\begin{array}{l}\text { Probability of avertive costs with respect to } \\
\text { changes in } \mathrm{Pb} \text { concentrations }(\mathrm{A} / \Delta \mathrm{L})\end{array}$ & 0.238 \\
\hline Mean work days lost & 9 \\
\hline Mean wage rate & 648 PKR \\
\hline Average medical expenses & $\begin{array}{l}10,260 \\
\text { PKR }\end{array}$ \\
\hline Average avertive costs & $\begin{array}{l}12,807 \\
\text { PKR }\end{array}$ \\
\hline
\end{tabular}

Average loss of earnings (Table 9)*col.2 (Table 9) $=$ $6,251 * 956.5=5,979,081.5$

Column 5.

Average cost of illness*P $(\mathrm{M} / \Delta \mathrm{C}) \quad 0.1367 * \operatorname{col} .2=$ $10,260 * 0.1367 * 956.500=1,341,531.4$

Column 6.

Average avertive cost* $\mathrm{P}(\mathrm{A} / \Delta \mathrm{C}) \quad 0.238^{*}$ col. $2=$ $12,807 * 0.238 * 956.500=2,915,475.1$

Column 7.

col.5+col.6 = 1,341,531.423 $+2,915,475.129=$ $4,257,006.552 \mathrm{PKR}=\$ 41,753.78$

\section{Discussion}

It is evident that $\mathrm{Pb}$ has adverse effects on health (Cabral et al., 2006) and thereby economic costs of $\mathrm{Pb}$ contamination at the household level has significant importance in devising stringent environmental regulations of a country. It was revealed that the households living closer $(100 \mathrm{~m})$ to the source of contamination (wastewater channel) were much exposed to the $\mathrm{Pb}$ contamination ( $\mathrm{Pb}$-induced sickness, 79\%) as compared to households located at increasing distances, i.e. $200 \mathrm{~m} \mathrm{(55 \% )}$ and $350 \mathrm{~m}(12 \%)$. This was verified from $\mathrm{Pb}$ concentrations in drinking water (Fig. 3).

$\mathrm{Pb}$ contamination was the most influential factor in all three dependent variables, i.e., sickness, medical cost, and avertive cost, which accounted for an increase of $19 \%$, $13 \%$, and $23 \%$, respectively, for one unit change in lead contamination. Both sickness and medical costs account for the $16 \%$ impact on households with respect to location from the wastewater channel. Moreover, the location is not found to be significant in the probability of avertive costs. The reason could be factors influencing the decisions on avertive measures, which further depend on income.

Avertive measures were found to be significant in the determination of probability of sickness and probability of medical costs [35], because avertive measures adopted by the household depended on the decision of opting for avertive measures, the type of avertive measures, the expenditure incurred on the avertive measures, knowledge of pollution, risk of disease, and income level. As the most expensive types of avertive measures were the installation of filter cartridges and the purchase of sealed bottles from the market, both these AMs relate to income level of the household, and the percentage adaption of these two methods were $16 \%$ (filter cartridge) and14\% (bottled water). However, a larger share in adoption of AM was boiling water (41\%) and using chemicals like chlorine (29\%) because of pollution awareness and risk perception.

Table 10. Total welfare loss due to $\mathrm{Pb}$ contamination in Dingi.

\begin{tabular}{|c|c|c|c|c|c|c|}
\hline $\begin{array}{c}\text { Population } \\
\text { at Risk }\end{array}$ & $\begin{array}{c}\text { Affected } \\
\text { population }\end{array}$ & $\begin{array}{c}\text { Total sick } \\
\text { days }\end{array}$ & WDL(PKR) & $\begin{array}{c}\text { Medical expenditure } \\
\text { (PKR) }\end{array}$ & $\begin{array}{c}\text { Avertive expenditure } \\
\text { (PKR) }\end{array}$ & $\begin{array}{c}\text { Welfare Loss } \\
\text { (PKR) }\end{array}$ \\
\hline$(1)$ & $(2)$ & $(3)$ & $(4)$ & $(5)$ & $(6)$ & $(7)$ \\
\hline 5021 & 956.500 & $8,608.504$ & $5,979,081.5$ & $1,341,531.423$ & $2,915,475.129$ & $4,257,006.552$ \\
\hline
\end{tabular}




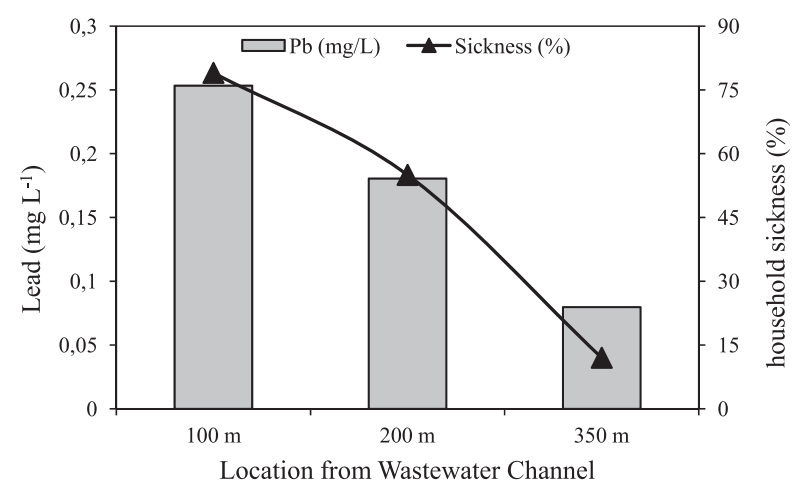

Fig. 3. Relationship between sickness and $\mathrm{Pb}$ concentration and distance from wastewater channel.

Accordingly, due to the low level of income, the households are not adapting the filter cartridge and bottled water. The major chunk in the avertive cost was of filter cartridges and bottled water for their unit price instead of their frequency. This was the main reason that AMs did not emerge as a significant variable in the determination of probability of avertive cost.

Education, pollution awareness, and perception of risk were expected to be influential factors in determining probabilities of sickness, medical costs, and avertive costs. Our study shows the different dimensions with respect to education and the informal education related to the environment, i.e., pollution awareness. Unexpectedly, we find that the people who have informal knowledge, i.e., general pollution, waterborne diseases, $\mathrm{Pb}$-associated diseases, testing of drinking water, and participation in NGO activity is more tilted toward the adoption of avertive measures. Therefore, pollution awareness and perception of risk are both variables that play a significant role in the reduction of probability of sickness and probability of medical cost, and so they were found to be highly significant. The contributions of pollution awareness and perception of risk were $18 \%$ and $6 \%$ in probability of sickness (Table 5), 20\% and $9 \%$ in probability of incurring medical (Table 6), and $25 \%$ and $13 \%$ in the probability of avertive cost (Table 7).

Unfortunately, our expectations for education went wrong in determining the probabilities of any dependent variable except in the probability of incurring avertive cost. Although education has not emerged as a significant factor for sickness and medical cost probabilities, it is significant in avertive cost. The results further exhibit that the average number of days lost in a year due to sickness is nine - a low number because most of the household members do their jobs even while ill and do not report sick days lost because of reduced earnings.

It is important to note that the people who are most involved in the religious practice of offering prayers have a larger chance of becoming sick. The reason is that members of the Muslim community offer prayer five times a day along with obligatory ablution (a ritualistic cleaning of parts of the body, including rinsing the mouth with available water). People who do this have much exposure to contaminated water, and thereby increase the prevalence of disease. Another important outcome of avertive behavior signifies a new trend that people from a poor income group do not expect any intervention for treatment of the water from the government and industry. Consequently, they have adopted themselves to the organized avertive activity of boiling water. As stated earlier, $79 \%$ of households use both boiling water and chlorine tablets; still, the impact of chlorination is not significant. People have made a routine practice of boiling water for drinking purposes. It is evident in our results that those who adopt the avertive measures have a low probability of sickness. Moreover, the households are not consistent in adopting the purchase of bottled water and installing the filter cartridge because of high initial costs and the maintenance costs. Their annual avertive cost is found to be $19 \%$ of the total economic cost of drinking water contamination.

The study also shows that households spend approximately 12,807 (PKR) or (\$125) yearly to face lead-associated illness. These expenditures are nearly $5 \%$ of the income of the households annually, which is a significant burden on the poor community. Therefore, households are compelled to switch their expenditures from the other utilities' head, which ultimately affects the respective household utility.

It is important to note that the old and rusted public health pipelines and tube wells are not functioning for several years because of energy crises in Pakistan. Based on the present investigations, we recommend the following initiatives be considered by the government and industry:

- Installation of new tube wells $600 \mathrm{~m}$ from wastewater channel.

- Replacement of rusted water pipelines.

- The government should install water filtration plants to purify and supply safe drinking water.

- The industrial estate must assure compliance of industrial effluent discharge limits as per EPA Pakistan guidelines.

- New schemes of the government of Pakistan for the supply of solar energy-driven tube wells can also be provided to such communities.

All this can reduce the loss of income, medical costs, avertive costs, the opportunity cost of leisure hour, the opportunity cost of avertive measures, and welfare loss of the already poor income households in Dingi.

\section{Conclusions}

Multidisciplinary approaches of economic theory and econometric estimation were applied at the household level to calculate the costs associated with $\mathrm{Pb}$ contamination and its associated health impacts. The study revealed that the community could be sensitized through the information dissemination campaign program pertaining to pollution awareness of the lack of resources in developing countries for the installation of a water treatment plant (approximately $\$ 5$ million). It can reduce 
the cost of illness. However, the formal education imparted in the schools and colleges did not show any significant influence in reducing the probability of sickness, which clearly indicated that there was no practical application of school knowledge in their real-life problems. A compromising behavior of the community was observed in Dingi when their lives were at threat. Results also showed that the community organized themselves at the household level through informal knowledge of $\mathrm{Pb}$ contamination, and they adopted avertive measures. These measures proved to be successful in reducing disease risks. The total welfare loss to households in Dingi exposed to $\mathrm{Pb}$ contamination was 4.26 million $\mathrm{PKR}(\$ 42,000)$. This welfare loss, if extrapolated on 20 more villages along the wastewater channel, account for a substantial monetary loss. Therefore, the government regulatory unit and industry are required to play an active role in mitigating water pollution, ill health, and welfare loss of community.

\section{Acknowledgements}

The authors are indebted to the COMSATS Institute of Information Technology for providing transport along the entire study period, and to Mr. Sajid and Mr. Sohail for their help inead determination in water and wastewater samples.

\section{References}

1. BOUGHERIRA N., HANI A., DJABRI L., TOUMI F., CHAFFAI H., HAIED N., NECHEM D., SEDRATI N., Impact of the urban and industrial waste water on surface and groundwater, in the region of Annaba, (Algeria). Energy Procedia. 50, 692, 2014.

2. HAQ M., MUSTAFA U., AHMAD I., Household's willingness to pay for safe drinking water: A case study of Abbottabad district. Pak Dev Rev. 46, 1137, 2007.

3. WHO, Safer water, better health: Costs, benefits and sustainability of interventions to protect and promote health. $1,2008$.

4. ERICSON B., CARAVANOS J., CHATHAM-STEPHENS K., LANDRIGAN P. FULLER R., Approaches to systematic assessment of environmental exposures posed at hazardous waste sites in the developing world: the Toxic Sites Identification Program. Environ Monit Assess. 185 (2), 1755, 2013

5. WEDGWORTH J.C., BROWN J., Limited access to safe drinking water and sanitation in Alabama's Black Belt: A cross-sectional case study. Water Qual Expo Health. 5 (2), 69, 2013.

6. KHAN K., LU Y., KHAN H., ZAKIR S., IHSANULLAH, KHAN S., KHAN A.A., WEI L., WANG T., Health risks associated with heavy metals in the drinking water of Swat, northern Pakistan. J Environ Sci. 25 (10), 2003, 2013.

7. TANEKHY M., Lead poisoning in Nile tilapia (Oreochromis niloticus): oxidant and antioxidant relationship. Environ Monit Assess. 187 (4), 1, 2015.

8. ASHBOLT N.J., Microbial Contamination of Drinking Water and Human Health from Community Water Systems. Curr Environ Health Rep. 2 (1), 95, 2015.
9. BATOOL U., JAVED M., Synergistic Effects of Metals (Cobalt, Chromium and Lead) in Binary and Tertiary Mixture Forms on Catla catla, Cirrhina mrigala and Labeo rohita. Pak J Zool. 47 (3), 617, 2015.

10. JAN F., ISHAQ A., KHAN S., SHAKIRULLAH M., ASIM S.M., AHMAD I., MABOOD F., Bioaccumulation of metals in human blood in industrially contaminated area. J Environ Sci. 23 (12), 2069, 2011.

11. LUY., SONG S., WANG R., LIU Z., MENG J., SWEETMAN A.J., JENKINS A., FERRIER R.C., LI H., LUO W., Impacts of soil and water pollution on food safety and health risks in China. Environ Int. 77, 5, 2015.

12. MEHTA., SBIHI H., DINH T.N., XUAN D.V., LE THI THANH L., THANH C.T., LE TRUONG G., COHEN A., BRAUER M., Effect of poverty on the relationship between personal exposures and ambient concentrations of air pollutants in Ho Chi Minh City. Atmos Environ. 95 (0), 571, 2014.

13. LUY., SONG S., WANG R., LIU Z., MENG J., SWEETMAN A.J., JENKINS A., FERRIER R.C., LI H., LUO W., WANG T., Impacts of soil and water pollution on food safety and health risks in China. Environ Int. 77, 5, 2015.

14. ZIETZ B., DASSEL DE VERGARA J., KEVEKORDES S., DUNKELBERG H., Lead contamination in tap water of households with children in Lower Saxony, Germany. Sci Total Environ. 275 (1-3), 19, 2001.

15. YOSHIDA T., YAMAUCHI H., FAN SUN G., Chronic health effects in people exposed to arsenic via the drinking water: dose-response relationships in review. Toxicol Appl Pharm. 198 (3), 243, 2004.

16. KUWAYAMA Y., OLMSTEAD S. 17. Water quality and economics: willingness to pay, efficiency, cost-effectiveness, and new research frontiers. Handbook on the Economics of Natural Resources 474, 2015.

17. KALAJDZIC P., KENIG B., ANDJELKOVIC M., Drosophila subobscura flies adapted to low lead concentration carry no fitness cost. Environ Pollut. 204, 90, 2015.

18. BOCKSTAEL N.E., FREEMAN A.M., Chapter 12 Welfare Theory and Valuation. In Handbook of Environmental Economics, Karl-Gran, M.; Jeffrey, R. V., Eds. Elsevier: 2, 517, 2005.

19. DASGUPTA P., Valuing health damages from water pollution in urban Delhi, India: a health production function approach. Environ Dev Econ. 9 (1), 83, 2004.

20. GIRI S., SINGH A.K., Human health risk assessment via drinking water pathway due to metal contamination in the groundwater of Subarnarekha River Basin, India. Environ Monit Assess. 187 (3), 1, 2015.

21. MAJUMDAR C., GUPTA G., The economic losses due to drinking water impurity: A revealed preference analysis in Kolkata, India. Indian Econ Rev. 44 (1), 125, 2009.

22. BIROL E., KAROUSAKIS K., KOUNDOURI P., Using economic valuation techniques to inform water resources management: A survey and critical appraisal of available techniques and an application. Sci Total Environ. 365 (1-3), $105,2006$.

23. POLYZOU E., JONES N., EVANGELINOS K.I., HALVADAKIS C.P., Willingness to pay for drinking water quality improvement and the influence of social capital. J Socio-Econ. 40 (1), 74, 2011.

24. DEL SAZ-SALAZAR S., HERNÁNDEZ-SANCHO F., SALA-GARRIDO R., The social benefits of restoring water quality in the context of the Water Framework Directive: A comparison of willingness to pay and willingness to accept. Sci Total Environ. 407 (16), 4574, 2009.

25. TSE M.S., CHAU C.K., LEE W.L., Assessing the benefit and 
cost for a voluntary indoor air quality certification scheme in Hong Kong. Sci Total Environ. 320 (2-3), 89, 2004.

26. CHAU C.K., HUI W.K., TSE M.S., Valuing the health benefits of improving indoor air quality in residences. Sci Total Environ. 394 (1), 25, 2008.

27. ROY J., Economic benefits of arsenic removal from ground water - A case study from West Bengal, India. Sci Total Environ. 397 (1-3), 1, 2008.

28. RIVE N., Climate policy in Western Europe and avoided costs of air pollution control. Econ Model. 27 (1), 103, 2010.

29. BENIE-BI J., CAMBON L., GRIMAUD O., KIVITS J., ALLA F., Health needs and public health functions addressed in scientific publications in Francophone sub-Saharan Africa. Public Health. 127 (9), 860, 2013.

30. CROPPER M.L., SIMON N.B., ALBERINI A., ARORA S., SHARMA P., The health benefits of air pollution control in Delhi. Am J Agr Econ. 79 (5), 1625, 1997.

31. SRIVASTAVA A., KUMAR R., Economic valuation of health impacts of air pollution in Mumbai. Environ Monit Assess. 75 (2), 135, 2002.
32. MANZOOR S., SHAH M.H., SHAHEEN N., KHALIQUE A., JAFFAR M., Multivariate analysis of trace metals in textile effluents in relation to soil and groundwater. J Hazard Mater. 137 (1), 31, 2006.

33. DESHOMMES E., LAROCHE L., NOUR S., CARTIER C., PRÉVOST M., Source and occurrence of particulate lead in tap water. Water Res. 44 (12), 3734, 2010.

34. NGUETA G., PRÉVOST M., DESHOMMES E., ABDOUS B., GAUVIN D., LEVALLOIS P., Exposure of young children to household water lead in the Montreal area (Canada): The potential influence of winter-to-summer changes in water lead levels on children's blood lead concentration. Environ Int. 73, 57, 2014.

35. ABDALLA C.W., ROACH B.A., EPP D.J., Valuing environmental quality changes using averting expenditures: an application to groundwater contamination. Land Econ. 68 (2), 163, 1992. 
